\title{
Avaliações estéticas de interfaces com distintos níveis de permeabilidade e proximidade com os espaços abertos públicos
}

\author{
Aesthetic evaluations of interfaces with different levels \\ of permeability and proximity to public open spaces
}

\section{Antônio Tarcísio da Luz Reis Ana Flávia Piva Panzenhagen Victoria Luvizetto Carpin Gerson}

\section{Resumo

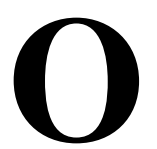

objetivo deste artigo é realizar avaliações estéticas de interfaces com distintos níveis de permeabilidade e proximidade com os espaços abertos públicos, por três grupos com diferentes níveis e tipos de formação, nomeadamente: arquitetos, não arquitetos com curso universitário e pessoas sem formação universitária. Estas interfaces urbanas são caracterizadas por: edifícações no interior do quarteirão, sem relação direta com a rua; edificações no perímetro do quarteirão, com portas e janelas voltadas para a rua; edificações com paredes cegas voltadas para a rua; muro de condomínio fechado junto à rua; muro com vegetação junto à rua, em condomínio fechado; e portas de garagens junto à rua. Os meios de coleta de dados incluem questionários preenchidos pelos três grupos de respondentes por meio do programa LimeSurvey, com acesso disponibilizado via internet. Testes estatísticos não paramétricos tais como Kruskal-Wallis e Kendal foram utilizados para analisar os dados. Os principais resultados mostram, por exemplo, que edifícações com paredes cegas, muros de condomínios fechados e edifícações com portas de garagem voltadas para as ruas tendem a produzir avaliações estéticas negativas por parte das pessoas, enquanto o oposto tende a ocorrer em relação às edificações no perímetro do quarteirão com portas e janelas voltadas para a rua.

Palavras-chave: Interfaces urbanas. Avaliações estéticas. Desenho urbano.

\section{Abstract}

The aim of this paper is to carry out aesthetic evaluations of interfaces with different levels of permeability and proximity to public open spaces, by three

${ }^{1}$ Antônio Tarcísio da Luz Reis ${ }^{1}$ Universidade Federal do Rio Grande Porto Alegre - RS - Brasil

2Ana Flávia Piva Panzenhagen ${ }^{2}$ Universidade Federal do Rio Grande do Sul Porto Alegre - RS - Brasil

${ }^{3}$ Victoria Luvizetto Carpin Gerson ${ }^{3}$ Universidade Federal do Rio Grande do Sul Porto Alegre - RS - Brasil

Recebido em 17/08/18 Aceito em 10/10/18 groups with different levels and types of educational background, namely: architects, non-architects college graduates and non college graduates. These urban interfaces are characterised by: buildings inside the blocks with no direct relationship with the street; buildings on the block perimeter with doors and windows facing the street; buildings with blind walls facing the street; gated condominium walls facing the street; gated condominiums' green walls facing the street; and garage doors facing the street. Data gathering means include questionnaires filled out by the three groups of respondents in the LimeSurvey software made available on the Internet. Non-parametric statistical tests such as Kruskal-Wallis and Kendal were used to analyse the data. The main results show, for example, that buildings with blind walls, gated condominium walls and buildings with garage doors facing the streets tend to produce negative aesthetic evaluations, while the opposite tends to occur with buildings on the block perimeter with doors and windows facing the street.

Keywords: Urban interfaces. Aesthetic evaluations. Urban design. 


\section{Introdução}

Interfaces significam, neste artigo, os limites entre os espaços abertos públicos das ruas e as áreas adjacentes, geralmente com edificações. Em ambientes urbanos tradicionais, tais interfaces urbanas tendem a ser caracterizadas por fachadas de edificações com portas e janelas voltadas para a rua (Figura 1) (BENTLEY et al., 2005; REIS, 2014a, 2014b). No entanto, esta relação direta entre edificações e espaços abertos públicos tem sido alterada pelo planejamento urbano modernista, em que as edificações tendem a estar localizadas no interior dos quarteirões e, frequentemente, com paredes cegas voltadas para as ruas (Figura 2) (ARSEGO; REIS, 2017; REIS, 2014a, 2014b; TRANCIK, 1986). Tais características têm se replicado em implantações modernistas em projetos de habitação de interesse social, de acomodações para atletas participantes de Jogos Pan-Americanos e Olímpicos, e de campi universitários (REIS, 2014a).

Além disso, em muitas cidades, os térreos nas fachadas principais das edificações, os espaços mais importantes na relação entre a edificação e a rua (GEHL, 2010, 2011), têm sido utilizados como garagens (Figura 3), em vez de abrigarem usos que possam contribuir para a vitalidade e qualidade de vida urbana. Adicionalmente, condomínios fechados (horizontais ou verticais) cercados por muros têm se proliferado por diversas áreas em distintos países, sejam áreas urbanas consolidadas (Figura 4), sejam na periferia das cidades ou em áreas menos ou não urbanizadas. Esses condomínios fechados, quando em áreas urbanas consolidadas caracterizadas por fachadas de edificações com portas e janelas voltadas para a rua, provocam uma ruptura nessas interfaces urbanas tradicionais com consequências na utilização e estética de espaços abertos públicos. Por exemplo, em estudo realizado em três condomínios fechados em áreas urbanas consolidadadas em Porto Alegre, os muros que delimitam esses condomínios caracterizam barreiras visuais desprovidas de estímulos visuais e tendem a ser percebidos como monótonos e a gerar um impacto estético negativo, desqualificando a experiência urbana e provocando uma redução no uso dos espaços abertos públicos adjacentes (BECKER; REIS, 2004). Entretanto, a Lei Complementar n. 741/2014 possibilita a construção, em Porto Alegre, de muros com até dois metros de altura voltados para os espaços abertos públicos (ARSEGO; REIS, 2017).
Por outro lado, a proximidade entre as edificações e a calçada e a existência de portas e janelas voltadas para a rua, características que tendem a estar presentes em áreas urbanas tradicionais, criam interfaces que potencializam a atração do pedestre e a socialização (GEHL, 2010). Embora este e outros estudos tenham mostrado e alguns autores tenham ressaltado (BENTLEY et al., 2005; JACOBS, 1984) as consequências negativas, para a qualidade dos espaços urbanos, da falta de interfaces tradicionais com portas e janelas voltadas para a rua, há necessidade de aprofundar o conhecimento sobre as avaliações estéticas de ruas caracterizadas por distintas interfaces urbanas, com distintos níveis de permeabilidade e de proximidade. Além disso, tem havido alguma controvérsia sobre a existência ou não de diferenças entre as avaliações estéticas de arquitetos e leigos. Alguns estudos (FAWCETT; ELLINGHAM; PLATT, 2008; NASAR, 1998) revelam a existência de diferenças entre as avaliações estéticas de arquitetos e de leigos. Por exemplo, diferenças significativas foram encontradas entre as preferências estéticas de arquitetos e leigos usuários de edifícios de escritórios com relação a suas fachadas (FAWCETT; ELLINGHAM; PLATT, 2008). Por outro lado, outros estudos revelam que quando as ideias de ordem e estímulo estão presentes em conjuntos de fachadas, ou na fachada de uma edificação, não existem diferenças significativas entre arquitetos, não arquitetos com formação universitária e pessoas sem tal formação (REIS; BIAVATTI; PEREIRA, 2011, 2014).

Assim, o objetivo deste trabalho é realizar avaliações estéticas de distintas interfaces urbanas entre edificações e espaços abertos públicos por três grupos com diferentes níveis e tipos de formação escolar, a saber: arquitetos, não arquitetos com curso universitário, e pessoas sem formação universitária. As interfaces urbanas são caracterizadas por: edificações no interior dos quarteirões sem relação direta com a rua; edificações no perímetro do quarteirão, com portas e janelas voltadas para a rua; edificações com paredes cegas voltadas para a rua; muros de condomínios fechados junto à rua; muros verdes de condomínios fechados junto à rua; e portas de garagens junto à rua. Assim, este estudo pode contribuir para a compreensão dos efeitos estéticos produzidos por distintas interfaces urbanas e, logo, para a qualificação das experiências estéticas dos usuários das cidades. 
Figura 1 - Edificações com aberturas junto ao espaço aberto público - Viena

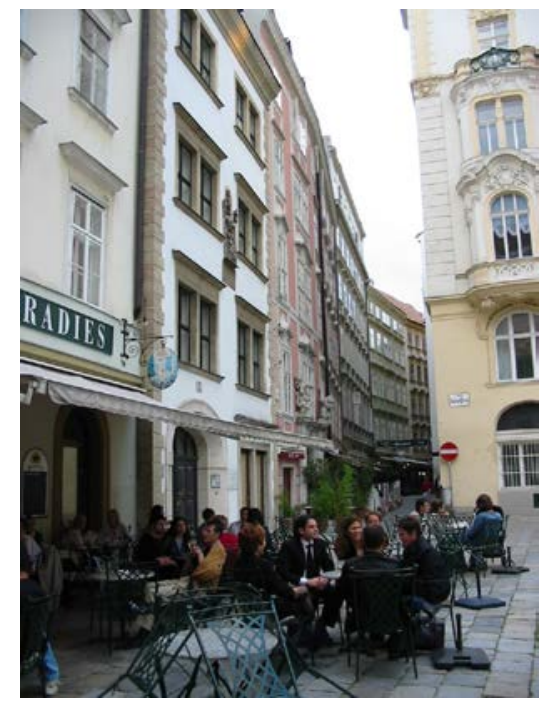

Figura 2 - Implantação modernista - Conj unto Killingworth, Inglaterra

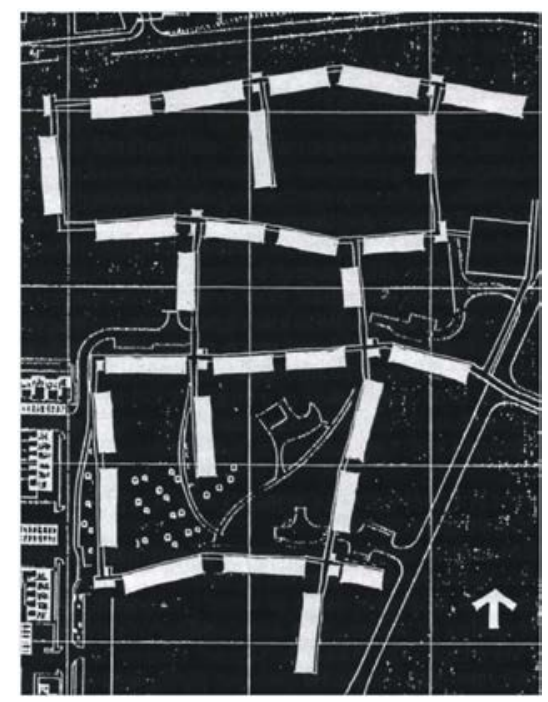

Figura 3 - Portas de garagens voltadas para a rua - Porto Alegre

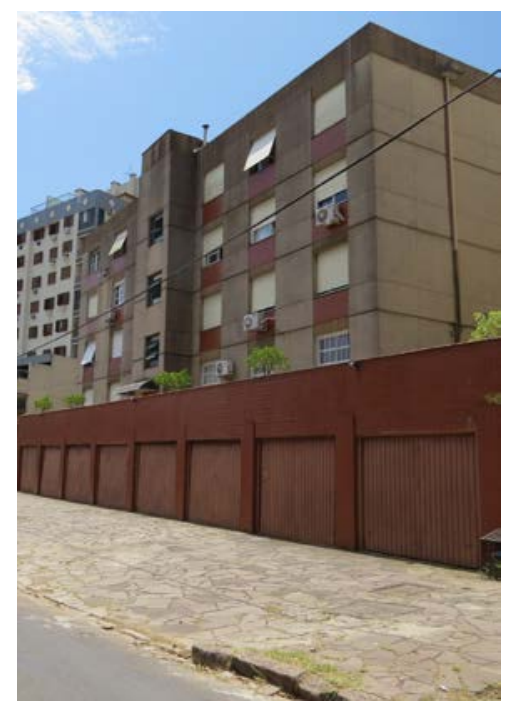

Avaliações estéticas de interfaces com distintos níveis de permeabilidade e proximidade com os espaços abertos 


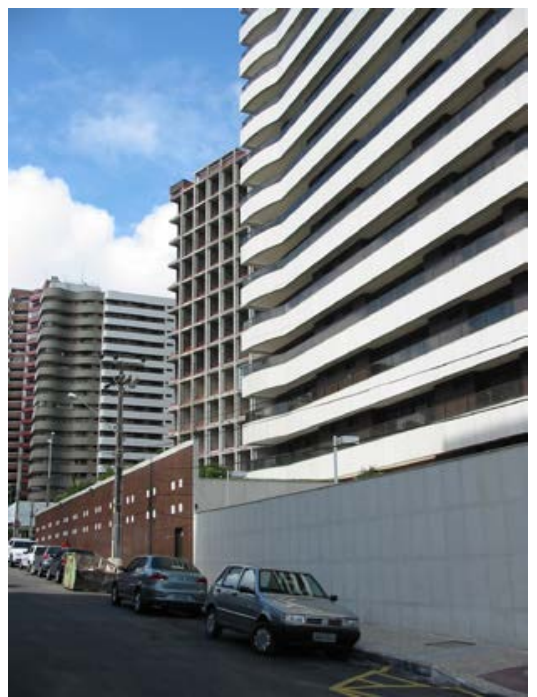

\section{Método}

A metodologia utilizada faz parte da área de estudos ambiente-comportamento, que tem por objetivo investigar as relações entre as características físico-espaciais do ambiente construído e as percepções dos indivíduos, utilizando métodos das ciências sociais (REIS; LAY, 2006). Assim, os métodos de coleta de dados incluem questionários respondidos pelos três grupos de respondentes no programa LimeSurvey disponibilizado via internet. $\mathrm{O}$ convite para participar da pesquisa foi enviado por e-mail a sindicatos de funcionários da Universidade Federal do Rio Grande do Sul (UFRGS), Universidade Federal de Ciências da Saúde de Porto Alegre (UFCSPA) e Instituto Federal do Rio Grande do Sul (IFRS), aos diretores e departamentos de várias faculdades da UFRGS, incluindo a Faculdade de Arquitetura, e para cursinhos prévestibulares. No total, 250 pessoas com diferentes níveis e tipos de formação acadêmica responderam ao questionário, conforme segue: 62 arquitetos, 169 não arquitetos com formação universitária e 19 pessoas sem formação universitária. Foram utilizadas questões de escolha simples para as avaliações estéticas de cenas com distintas interfaces urbanas, e questões de múltipla escolha sobre as preferências e justificativas para tais preferências, tais como: "Você acha a aparência da cena: [ ] Muito bonita, [ ] Bonita, [ ] Nem bonita nem feia, [ ] Feia, [ ] Muito feia"; "Ordene as cenas, da mais (1) para a menos (3) preferida quanto à aparência: [ ] Cena A, [ ] Cena B, [ ] Cena C"; "Indique as principais razões que justifiquem a cena mais preferida quanto à aparência: [ ] Presença de edificações com aberturas para a rua, [ ] Relação direta das edificações com a rua, [ ] Outros: ...". Doze cenas (quatro conjuntos com três cenas em cada; Figuras 5 a 8) que representam as interfaces urbanas foram editadas e apresentadas nos questionários. Cada cena é formada pela combinação de duas fotografias coloridas editadas de ruas em Porto Alegre. Alguns itens (tais como: céus com distintas características, latas de lixo, postes e fios de luz) que poderiam afetar a avaliação estética das interfaces urbanas e as preferências por elas foram removidos das cenas através do programa Adobe Photoshop CS6. As cenas também têm níveis semelhantes de iluminação natural, com pouca ou nenhuma incidência solar, para evitar grandes contrastes e sombras nos prédios.

A utilização de fotografias coloridas para a representação das distintas interfaces urbanas está fundamentada em seus usos recorrentes em estudos envolvendo avaliações estéticas e na adequação dessas fotografias para simular um ambiente real (SANOFF, 1991). As fotografias que compõem as cenas possuem diferentes perspectivas formadas a partir de distintos pontos de observação devido ao fato de as fotografias terem sido tiradas a partir de pontos que possibilitavam uma adequada visualização das interfaces e que variavam de rua para rua, devido aos diferentes tipos de obstáculos e barreiras visuais existentes (p. ex., árvores, depósitos de lixo, postes e fios de luz). Assim, além das diferenças das próprias interfaces em distintas ruas (incluindo calçadas com larguras variadas), as diferenças nos pontos de observação (a partir dos quais as fotos foram tiradas) fizeram com que as montagens das cenas com duas fotografias resultassem em cenas com distintas perspectivas e larguras das calçadas e pistas de trânsito de veículos. Contudo, os ângulos de visão utilizados para as fotografias não têm um efeito 
significativo sobre as avaliações estéticas, sendo determinantes para tais avaliações os elementos arquitetônicos existentes (STAMPS, 2000). Corroborando tal argumento, as variações entre as perspectivas das cenas não comprometeram as avaliações e as comparações entre as cenas em cada conjunto (com três cenas), conforme revelado pelos testes realizados (antes da aplicação do questionário) para verificar a adequação das cenas para representarem as diferentes categorias de interfaces consideradas na pesquisa. Ainda, nas justificativas para as cenas mais e menos preferidas foi incluída no questionário a alternativa “Outros: ...”, possibilitando ao respondente incluir, por exemplo, uma justificativa relacionada a alguma possível diferença entre as cenas. Para obter a combinação certa de duas fotografias (uma para cada lado da rua) em cada uma das 12 cenas que representam as interfaces urbanas, e verificar a adequação das perguntas, foram realizados três testes pilotos.

Os dados no programa LimeSurvey foram transferidos e analisados no programa estatístico PASW Statistics 18 mediante testes estatísticos não paramétricos, tais como Kruskal-Wallis e Kendall W. O primeiro identifica, por exemplo, a existência de uma diferença estatisticamente significativa (sig. $\leq 0,05)$ entre as avaliações de cada uma das 12 cenas pelos três grupos de respondentes. O último revela, por exemplo, a existência de uma diferença estatisticamente significativa entre as avaliações das três cenas em cada um dos quatro conjuntos por cada um dos três grupos de respondentes.

\section{Resultados}

Uma diferença estatisticamente significativa foi encontrada entre os arquitetos, os não arquitetos com curso universitário e aqueles sem curso universitário em relação à avaliação das cenas urbanas A (Kruskal-Wallis, teste estatístico =
13,127, sig. $=0,001)$, $\mathrm{B}$ (Kruskal-Wallis, teste estatístico $=16,12$, sig. $=0,000)$ e C (KruskalWallis, teste estatístico $=16,41$, sig. $=0,000)$ (Figura 5 e Tabela 1). As cenas urbanas A (edifícios no interior da quadra sem relação direta com a rua) e C (edifícios com empena cega voltada para a rua) são claramente mais bem avaliadas por aqueles sem formação universitária (avaliações positivas: A - 57,9\%; C - 27,3\%) e mais mal avaliadas pelos arquitetos (avaliações positivas: A - 22,6\%; C - 5,8\%), embora as avaliações positivas não sejam expressivas em nenhum dos dois grupos. Logo, tende a haver um maior grau de exigência nas avaliações estéticas por parte dos arquitetos e um menor grau de exigência por parte daqueles sem formação universitária.

Comparando as avaliações individuais de cada uma das três cenas por cada grupo de respondente, encontrou-se uma diferença estatisticamente significativa entre as avaliações das cenas urbanas $\mathrm{A}, \mathrm{B}$ e $\mathrm{C}$ pelos arquitetos (Kendall W, teste estatístico $=39,487$, sig. $=0,000)$, pelos não arquitetos com curso universitário (Kendall W, teste estatístico $=74,968$, sig. $=0,000)$ e por aqueles sem formação universitária (Kendall W, teste estatístico $=9,0$, sig. $=0,011)$. Os arquitetos avaliaram melhor a cena B (edifícios no perímetro da quadra com janelas e portas voltadas para a rua; $37,5 \%$ de avaliações positivas e $21,4 \%$ de avaliações negativas) e pior a cena $\mathrm{C}$ (edifícios com paredes cegas junto à rua - 5,8\% de avaliações positivas e 76,9 \% de negativas). Para os outros dois grupos (não arquitetos com formação universitária e pessoas sem formação universitária), a cena C também é a pior (respectivamente: $9,6 \%$ e $27,3 \%$ de avaliações positivas, $60,3 \%$ e $18,2 \%$ de negativas) enquanto a cena A (edifícios no interior do quarteirão sem relação direta com a rua - respectivamente: $37,8 \%$ e $57,9 \%$ de avaliações positivas, $23 \%$ e $15,8 \%$ de negativas) é a mais bem avaliada.

Figura 5 - Cenas urbanas A, B e C

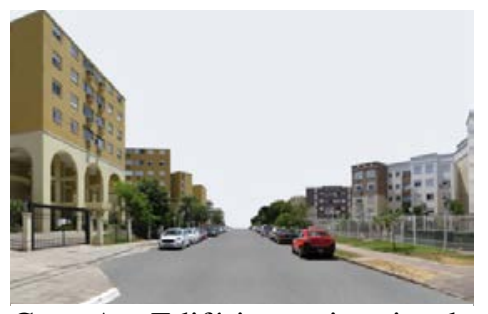

Cena A - Edifícios no interior da quadra sem relação direta com a rua

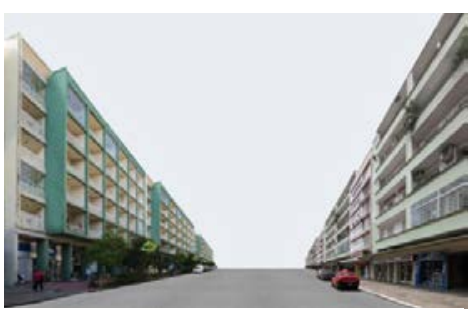

Cena B - Edifícios no perímetro da quadra com janelas e portas voltadas para a rua

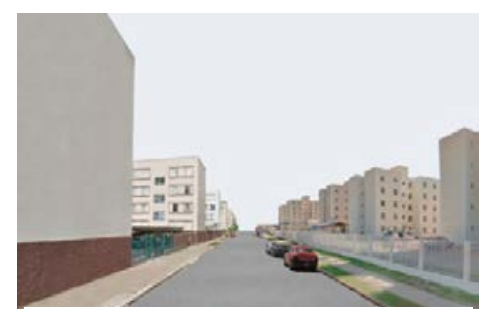

Cena C - Edifícios com empena cega voltada para a rua 
Tabela 1 - Graus de satisfação com as cenas urbanas A, B e C

\begin{tabular}{c|c|c|c|c|c|c|c}
\hline & $\begin{array}{c}\text { Muito } \\
\text { bonita }\end{array}$ & Bonita & $\begin{array}{c}\text { Nem bonita, } \\
\text { nem feia }\end{array}$ & Feia & $\begin{array}{c}\text { Muito } \\
\text { feia }\end{array}$ & $\begin{array}{c}\text { mvo } \\
\text { Kendall }\end{array}$ & $\begin{array}{c}\text { mvo } \\
\text { K-W }\end{array}$ \\
\hline \multicolumn{7}{c}{ Arquitetos (total de respondentes para cada cena: A=62; B=56; C=52) } \\
\hline Cena A & $2(3.2)$ & $12(19.4)$ & $25(40.3)$ & $16(25.8)$ & $7(11.3)$ & 2.15 & 103.15 \\
Cena B & $3(5.4)$ & $18(32.1)$ & $23(41.1)$ & $11(19.6)$ & $1(1.8)$ & 2.43 & 140.24 \\
Cena C & 0.0 & $3(5.8)$ & $9(17.3)$ & $23(44.2)$ & $17(32.7)$ & 1.41 & 84.46 \\
\hline Não arquitetos com formação universitária (total de respondentes para cada cena: A=169; B=163; C=146) \\
\hline Cena A & $9(5.3)$ & $55(32.5)$ & $66(39.1)$ & $31(18.3)$ & $8(4.7)$ & 2.44 & 129.30 \\
Cena B & $5(3.1)$ & $27(16.6)$ & $61(37.4)$ & $54(33.1)$ & $16(9.8)$ & 1.95 & 106.88 \\
Cena C & $1(0.7)$ & $13(8.9)$ & $44(30.1)$ & $63(43.2)$ & $25(17.1)$ & 1.61 & 108.38 \\
\hline Pessoas sem formação universitária (total de respondentes para cada cena: A=19; B=16; C=11) \\
\hline Cena A & $6(31.6)$ & $5(26.3)$ & $5(26.3)$ & $3(15.8)$ & 0.0 & 2.41 & 164.66 \\
Cena B & $2(12.5)$ & $7(43.8)$ & $3(18.8)$ & $4(25)$ & 0.0 & 2.27 & 153.47 \\
Cena C & 0.0 & $3(27.3)$ & $6(54.5)$ & $2(18.2)$ & 0.0 & 1.32 & 157.27 \\
\hline
\end{tabular}

Nota: $\mathrm{mvo}$ Kendall $=$ média dos valores ordinais obtidos por meio do teste de Kendall $\mathrm{W}$ (valores devem ser comparados para cada um dos três grupos de respondentes; valor mais alto indica cena mais satisfatória); mvo K-W = média dos valores ordinais obtidos por meio do teste Kruskal-Wallis (valores devem ser comparados para cada um dos três tipos de cenas; valor mais alto indica cena mais satisfatória); os valores entre parênteses representam percentagens em relação ao número total de respondentes em cada cena; o número de respondentes pode variar em relação à avaliação de cada cena, já que algumas perguntas não foram respondidas por todos em cada um dos três grupos de respondentes.

Uma diferença estatisticamente significante também foi encontrada entre a ordem de preferência das cenas urbanas $\mathrm{A}$, B e C pelos arquitetos (Kendall $\mathrm{W}$, teste estatístico $=34,125$, sig. $=0,000)$, pelos não arquitetos com formação universitária (Kendall W, teste estatístico = $107,324$, sig. $=0,000)$ e por aqueles sem formação universitária (Kendall W, teste estatístico = 11,091, sig. $=0,004)$. Confirmando os resultados anteriores sobre avaliações das cenas individuais, a cena A é a preferida pelos não arquitetos com formação universitária e por aqueles sem formação universitária, e a cena C é a menos preferida pelos arquitetos e pelos não arquitetos com formação universitária (Tabela 2). Embora a cena A tenha recebido a menor quantidade de pontos por parte dos arquitetos (78 - Tabela 2) a cena B (a mais bem avaliada individualmente por este grupo) foi selecionada como a preferida por um maior número de arquitetos (23 - Tabela 3 ) do que a cena A (22 - Tabela 3). Ainda, embora a cena B seja a menos preferida por aqueles sem formação universitária, é seguida de perto pela cena C (a mais mal avaliada individualmente).

As preferências pela cena A estão relacionadas, principalmente, à percepção da presença de edificações com aberturas para a rua $(54,5 \%$ de 22 arquitetos; 41,7\% de 108 não arquitetos com formação; $50 \%$ de 10 pessoas sem formação) e à percepção pelos não arquitetos da existência de relação direta com a rua $(42,6 \%$ de 108 não arquitetos com formação; $40 \%$ de 10 pessoas sem formação) (Tabela 3). A preferência dos arquitetos pela cena $\mathrm{B}$ deve-se à relação direta das edificações com a rua (87\% de 23) e da existência de aberturas voltadas para a rua (60,9\% de 23$)$. Por outro lado, a cena $\mathrm{C}$ tende a ser a menos preferida devido à presença de muros $\mathbf{( 5 8 , 3 \%}$ de 36 arquitetos; 33,3 \% de 75 não arquitetos com formação; $75 \%$ de 4 pessoas sem formação) e à falta de relação direta com a rua (75\% de 36 arquitetos; 66,7\% de 75 não arquitetos com formação; $50 \%$ de 4 pessoas sem formação) (Tabela 3). A menor preferência da cena B pelas pessoas sem formação (6) se justifica pela falta de espaço entre as edificações (50\%) e pela falta de relação direta das edificações com a rua $(33,3 \%)$.

Uma diferença estatisticamente significante foi encontrada entre as avaliações estéticas das cenas urbanas D (Kruskal-Wallis, teste estatístico = 29,735, sig. $=0,000$ ) e E (Kruskal-Wallis, teste estatístico $=10,823$, sig. $=0,004)$ pelos arquitetos, não arquitetos com formação universitária e por aqueles sem formação universitária (Figura 6; Tabela 4), embora tal diferença não tenha sido encontrada em relação à cena $\mathrm{F}$, caracterizada por edificações no perímetro do quarteirão com portas e janelas voltadas para a rua (Figura 6). As cenas urbanas D (condomínios fechados com muros junto à rua) e E (condomínio fechado com muro junto à rua e edificações no perímetro do quarteirão com portas e janelas voltadas para a rua; Figura 6) são, claramente, mais bem avaliadas por aqueles sem formação universitária e pior avaliadas pelos arquitetos (Tabela 4).

Portanto, as diferenças nas respostas estéticas dos três grupos em relação às cenas D e E indicam que aqueles sem formação universitária tendem a ter um menor grau de exigência estética enquanto o oposto ocorre com os arquitetos. No entanto, 
mesmo para esses sem formação universitária, as avaliações positivas da cena D (40\%) e E (50\%) são inexpressivas.

Tabela 2 - Ordem de preferência quanto à aparência das três cenas

\begin{tabular}{c|c|c|c|c|c|c|c|c}
\hline \multicolumn{3}{c|}{$\begin{array}{c}\text { Arquitetos (48 } \\
\text { respondentes) }\end{array}$} & \multicolumn{2}{c|}{$\begin{array}{c}\text { Não arquitetos com formação } \\
\text { (139 respondentes) }\end{array}$} & \multicolumn{3}{c}{$\begin{array}{c}\text { Pessoas sem formação } \\
\text { (11 respondentes) }\end{array}$} \\
\hline Cena & mvo K & mvo K-W & Cena & mvo K & mvo K-W & Cena & mvo K & mvo K-W \\
\hline $\mathrm{A}(78)$ & 1.62 & 122.48 & $\mathrm{~A}(180)$ & 1.29 & 92.99 & $\mathrm{~A}(13)$ & 1.18 & 81.45 \\
$\mathrm{~B}(81)$ & 1.69 & 69.69 & $\mathrm{~B}(314)$ & 2.24 & 108.50 & $\mathrm{~B}(27)$ & 2.45 & 124.09 \\
$\mathrm{C}(129)$ & 2.69 & 115.28 & $\mathrm{C}(343)$ & 2.47 & 95.42 & $\mathrm{C}(26)$ & 2.36 & 82.14 \\
\hline
\end{tabular}

Nota: mvo K =média dos valores ordinais obtidos por meio do teste de Kendall W; estes valores devem ser comparados na coluna, considerando-se o menor valor como indicador da maior preferência; mvo K-W = média dos valores ordinais obtidos por meio do teste Kruskal-Wallis; estes valores devem ser comparados na linha de cada cena, considerando-se o menor valor como indicador da maior preferência; os valores entre parênteses representam o somatório dos pontos recebidos por cada cena em cada um dos três grupos de respondentes, com cada um destes atribuindo valores de 1 (para a cena preferida) a 3 (para a cena menos preferida); assim, quanto menor o valor entre parênteses, maior a preferência pela cena.

Tabela 3 - J ustificativas quanto às preferências pelas cenas

\begin{tabular}{l|c|c|c}
\hline \multicolumn{1}{c|}{ Justificativa } & Arquitetos & $\begin{array}{c}\text { Não arquitetos } \\
\text { com formação }\end{array}$ & $\begin{array}{c}\text { Pessoas sem } \\
\text { formação }\end{array}$ \\
\hline \multicolumn{3}{c}{ Cena mais preferida = A (arquitetos = 22; não arquitetos = 108; sem formação = 10) } \\
\hline Presença de edificações com aberturas para a rua & $54,5(12)$ & $41,7(45)$ & $50(5)$ \\
\hline Relação direta das edificações com a rua & $18,2(4)$ & $42,6(46)$ & $40(4)$ \\
\hline Presença de vegetação & $18,2(4)$ & $20,4(22)$ & 0 \\
\hline \multicolumn{4}{c|}{ Cena mais preferida = B (arquitetos = 23; não arquitetos = 21; sem formação =1) } \\
\hline Presença de edificações com aberturas para a rua & $60,9(14)$ & $52,4(11)$ & $100(1)$ \\
Relação direta das edificações com a rua & $87(20)$ & $71,4(15)$ & 0 \\
\hline \multicolumn{4}{c}{ Cena menos preferida = C (arquitetos = 36; não arquitetos = 75; sem formação = 4) } \\
\hline Presença de muros & $58,3(21)$ & $33,3(25)$ & $75(3)$ \\
\hline Falta de relação direta das edificações com a rua & $75(27)$ & $66,7(50)$ & $50(2)$ \\
\hline \multicolumn{4}{c}{ Cena menos preferida = B (arquitetos = 8; não arquitetos = 55; sem formação = 6) } \\
\hline Falta de relação direta das edificações com a rua & $62,5(5)$ & $34,5(19)$ & $33,3(2)$ \\
\hline Falta de espaço entre edificações & 0 & $20(11)$ & $50(3)$ \\
\hline
\end{tabular}

Nota: os valores fora dos parênteses representam percentuais em relação ao total de respondentes em cada um dos três grupos que indicou a cena como mais ou menos preferida; são apresentadas as justificativas mencionadas pelo menos por $20 \%$ dos respondentes em um dos três grupos.

Figura 6 - Cenas urbanas D, E e F

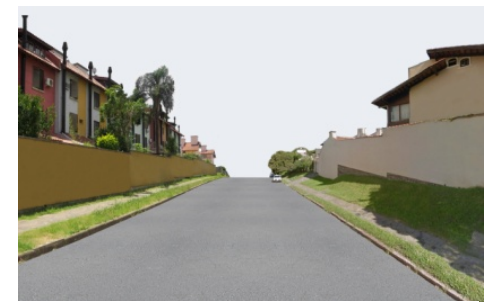

Cena D - Condomínios fechados com muros junto à rua

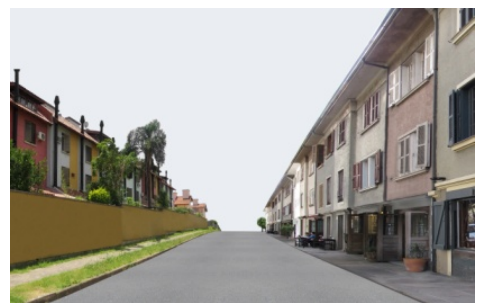

Cena E - Condomínio fechado com muro junto à rua - edifícações no perímetro da quadra com janelas e portas voltadas para a rua

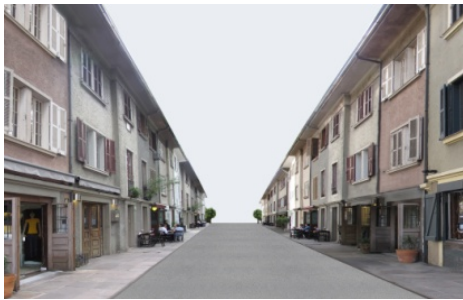

Cena F - Edificações no perímetro da quadra com janelas e portas voltadas para a rua 
Tabela 4 - Graus de satisfação com cenas urbanas D, E e F

\begin{tabular}{c|c|c|c|c|c|c|c}
\hline & $\begin{array}{c}\text { Muito } \\
\text { bonita }\end{array}$ & Bonita & Nem bonita, nem feia & Feia & Muito feia & $\begin{array}{c}\text { Mvo } \\
\text { Kendall }\end{array}$ & $\begin{array}{c}\text { Mvo } \\
\text { K-W }\end{array}$ \\
\hline \multicolumn{7}{c}{ Arquitetos (total de respondentes para cada cena =49) } \\
\hline Cena D & 0.0 & $3(6.1)$ & $9(18.4)$ & $15(30.6)$ & $22(44.9)$ & 1.38 & 61.02 \\
\hline Cena E & 0.0 & $3(6.1)$ & $18(36.7)$ & $21(42.9)$ & $7(14.3)$ & 1.80 & 75.36 \\
\hline Cena F & $9(18.4)$ & $27(55.1)$ & $11(22.4)$ & $1(2)$ & $1(2)$ & 2.83 & 103.18 \\
\hline \multicolumn{7}{c}{ Não arquitetos com formação universitária (total de respondentes para cada cena $=130)$} \\
\hline Cena D & $6(4.6)$ & 28(21.5) & $40(30.8)$ & $42(32.3)$ & $14(10.8)$ & 1.77 & 104.95 \\
\hline Cena E & $2(1.5)$ & $28(21.5)$ & $50(38.5)$ & $42(32.3)$ & $8(6.2)$ & 1.77 & 100.45 \\
\hline Cena F & $19(14.6)$ & $64(49.2)$ & $27(20.8)$ & $17(13.1)$ & $3(2.3)$ & 2.47 & 90.94 \\
\hline \multicolumn{7}{c}{ Pessoas sem formação universitária (total de respondentes para cada cena $=10)$} \\
\hline Cena D & $2(20)$ & $2(20)$ & $4(40)$ & $2(20)$ & 0.0 & 2.00 & 132.10 \\
\hline Cena E & $1(10)$ & $4(40)$ & $2(20)$ & $2(20)$ & $1(10)$ & 1.80 & 120.35 \\
\hline Cena F & $1(10)$ & $8(80)$ & 0.0 & $1(10)$ & 0.0 & 2.20 & 107.70 \\
\hline
\end{tabular}

Nota: mvo Kendall = média dos valores ordinais obtidos por meio do teste de Kendall $\mathrm{W}$ (valores devem ser comparados para cada um dos três grupos de respondentes; valor mais alto indica cena mais satisfatória); mvo K-W = média dos valores ordinais obtidos por meio do teste Kruskal-Wallis (valores devem ser comparados para cada um dos três tipos de cenas; valor mais alto indica cena mais satisfatória); os valores entre parênteses representam percentagens em relação ao número total de respondentes em cada cena.

Uma diferença estatisticamente significativa também foi encontrada entre as avaliações individuais das cenas D, E e F pelos arquitetos (Kendall W, teste estatístico $=68,038$, sig. $=$ 0,000) e pelos não arquitetos com formação universitária (Kendall W, teste estatístico = 60,504, sig. $=0,000$ ). A cena $F$ (edificações no perímetro da quadra com janelas e portas voltadas para a rua) é a mais bem avaliada (73,5\% de avaliações positivas), enquanto a cena D (condomínios fechados com muros junto à rua) é a mais mal avaliada (6,15\% de avaliações positivas) pelos arquitetos. A cena $\mathrm{F}$ também é a mais bem avaliada (63,8\% de avaliações positivas), enquanto a cena $\mathrm{D}$ e a cena $\mathrm{E}$ (condomínio fechado com muro junto à rua - edifícações no perímetro da quadra com janelas e portas voltadas para a rua) são as mais mal avaliadas pelos não arquitetos com formação universitária, respectivamente, com apenas $26,1 \%$ e $23 \%$ de avaliações positivas (Tabela 4). Não foi encontrada diferença estatisticamente significativa entre as avaliações das três cenas por aqueles sem formação universitária (Kendall W).

Adicionalmente, foi encontrada uma diferença estatisticamente significativa entre a ordem de preferência das cenas urbanas $\mathrm{D}, \mathrm{E}$ e $\mathrm{F}$ pelos arquitetos (Kendall W, teste estatístico $=52,898$, sig. $=0,000)$ e pelos não arquitetos com formação universitária (Kendall W, teste estatístico = 23,747, sig. $=0,000)$ (Tabela 5).

Confirmando os resultados anteriores sobre as avaliações de cenas individuais, a cena $\mathrm{F}$ (edificações no perímetro do quarteirão com portas e janelas voltadas para a rua) é a preferida pelos arquitetos e pelos não arquitetos com formação universitária, enquanto a cena $\mathrm{D}$ (muros de condomínios fechados junto à rua) é a menos preferida por esses dois grupos. Por outro lado, não foi encontrada diferença estatisticamente significativa entre as preferências por essas três cenas por aqueles sem formação universitária (Kendall W). Portanto, as evidências mostram que a cena $\mathrm{F}$ gerou as melhores respostas estéticas pelos dois grupos com formação universitária devido à presença de edificações com aberturas voltadas para a rua, selecionada por $90,2 \%$ dos 41 arquitetos e por $89 \%$ dos 73 não arquitetos com formação universitária que preferiram tal cena. Por outro lado, a cena D provocou as piores respostas estéticas por esses dois grupos, fundamentalmente devido à presença de muros, indicada por $97,6 \%$ dos 41 arquitetos e por 93,8\% dos 64 não arquitetos com formação para os quais a cena D foi a menos preferida (Tabela 6). Não foi encontrada uma diferença estatisticamente significativa entre as preferências pelas cenas $\mathrm{D}, \mathrm{E}$ e $\mathrm{F}$ por parte daqueles sem formação universitária.

Uma diferença estatisticamente significativa foi encontrada entre as avaliações da cena urbana $G$ (Kruskal-Wallis, teste estatístico $=25.655$, sig. $=$ 0,000 ) pelos arquitetos, não arquitetos com formação universitária e por aqueles sem tal formação. Por outro lado, não foi encontrada diferença estatisticamente significativa (teste Kruskal-Wallis) entre as avaliações das cenas $\mathrm{H}$ (muro verde de condomínio fechado voltado para a rua e edificações no perímetro da quadra com portas e janelas voltadas para a rua) e I (edificações no perímetro da quadra com portas e janelas voltadas para a rua) por esses três grupos

266 Reis, A. T. da L.; Panzenhagen, A. F. P.; Gerson, V. L. C. 
(Figura 7; Tabela 7). A cena urbana $G$ é claramente mais bem avaliada por aqueles sem formação universitária $(90 \%$ de avaliações positivas) e mais mal avaliada pelos arquitetos (52,1\% de avaliações positivas) (Tabela 7).
Portanto, quando existe uma diferença estatisticamente significativa, a resposta estética mais positiva é daqueles sem formação universitária, enquanto a menos positiva é dos arquitetos.

Tabela 5 - Ordem de preferência quanto à aparência

\begin{tabular}{c|c|c|c|c|c|c|c|c}
\hline \multicolumn{3}{c|}{$\begin{array}{c}\text { Arquitetos (49 } \\
\text { respondentes) }\end{array}$} & \multicolumn{2}{c|}{$\begin{array}{c}\text { Não arquitetos com formação } \\
\text { (126 respondentes) }\end{array}$} & \multicolumn{2}{c}{$\begin{array}{c}\text { Pessoas sem formação (10 } \\
\text { respondentes) }\end{array}$} \\
\hline Cena & mvo K & mvo K-W & Cena & mvo K & mvo K-W & Cena & mvo K & mvo K-W \\
\hline $\mathrm{D}(134)$ & 2.73 & 116.27 & $\mathrm{D}(284)$ & 2.26 & 86.67 & $\mathrm{D}(18)$ & 1.80 & 58.80 \\
$\mathrm{E}(98)$ & 2.00 & 86.87 & $\mathrm{E}(260)$ & 2.08 & 93.82 & $\mathrm{E}(22)$ & 2.20 & 103.60 \\
$\mathrm{~F}(62)$ & 1.27 & 74.67 & $\mathrm{~F}(211)$ & 1.66 & 98.29 & $\mathrm{~F}(20)$ & 2.00 & 116.10 \\
\hline
\end{tabular}

Nota: mvo K =média dos valores ordinais obtidos por meio do teste de Kendall W; estes valores devem ser comparados na coluna, considerando-se o menor valor como indicador da maior preferência; mvo K-W = média dos valores ordinais obtidos por meio do teste Kruskal-Wallis; estes valores devem ser comparados na linha de cada cena, considerando-se 0 menor valor como indicador da maior preferência; os valores entre parênteses representam o somatório dos pontos recebidos por cada cena em cada um dos três grupos de respondentes, com cada um destes atribuindo valores de 1 (para a cena preferida) a 3 (para a cena menos preferida); assim, quanto menor o valor entre parênteses, maior a preferência pela cena.

Tabela 6 - J ustificativa quanto à preferência da cena

\begin{tabular}{|c|c|c|c|}
\hline Justificativa & Arquitetos & $\begin{array}{c}\text { Não arquitetos } \\
\text { com formação }\end{array}$ & $\begin{array}{c}\text { Pessoas sem } \\
\text { formação }\end{array}$ \\
\hline \multicolumn{4}{|c|}{ Cena mais preferida $=\mathrm{F}$ (arquitetos $=41$, não arquitetos com formação $=73$, pessoas sem formação $=4$ ) } \\
\hline Presença de edificação com abertura para a rua & $90,2(37)$ & $89(65)$ & $75(3)$ \\
\hline \multicolumn{4}{|c|}{ Cena mais preferida $=\mathrm{D}$ (arquitetos $=5$, não arquitetos com formação $=32$, pessoas sem formação $=4$ ) } \\
\hline Existência de área gramada & $60(3)$ & $62,5(20)$ & $100(4)$ \\
\hline Existência de árvore & $40(2)$ & $53,1(17)$ & $50(2)$ \\
\hline \multicolumn{4}{|c|}{ Cena menos preferida $=\mathrm{D}$ (arquitetos $=41$, não arquitetos com formação $=64$, pessoas sem formação $=2$} \\
\hline Presença de muros & $97,6(40)$ & $93,8(60)$ & $100(2)$ \\
\hline \multicolumn{4}{|c|}{ Cena menos preferida $=\mathrm{E}$ (arquitetos $=3$, não arquitetos com formação $=30$, pessoas sem formação $=4$ ) } \\
\hline Presença de muros & $100(3)$ & $40(12)$ & $75(3)$ \\
\hline Excesso de informação & $33,3(1)$ & 33,3 (10) & 0 \\
\hline
\end{tabular}

Nota: os valores fora dos parênteses representam percentuais em relação ao total de respondentes em cada um dos três grupos que indicou a cena como mais ou menos preferida; são apresentadas as justificativas mencionadas pelo menos por $20 \%$ dos respondentes em um dos três grupos.

Figura 7 - Cenas urbanas $\mathbf{G}, \mathbf{H}$ e I

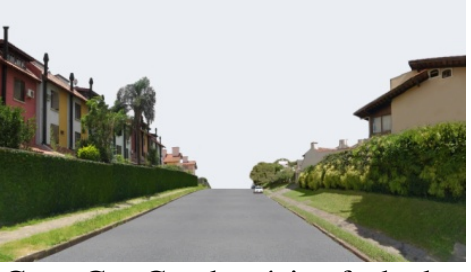

Cena G - Condomínios fechados com muros verdes junto à rua

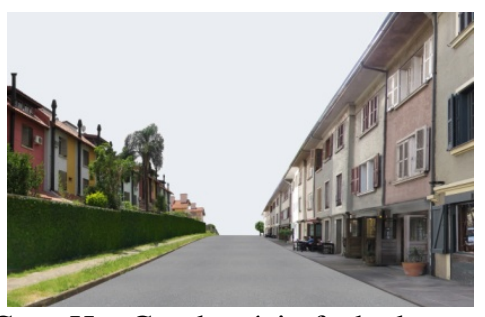

Cena $\mathrm{H}$ - Condomínio fechado com muro verde junto à rua - edificações no perímetro da quadra com janelas e portas voltadas para a rua

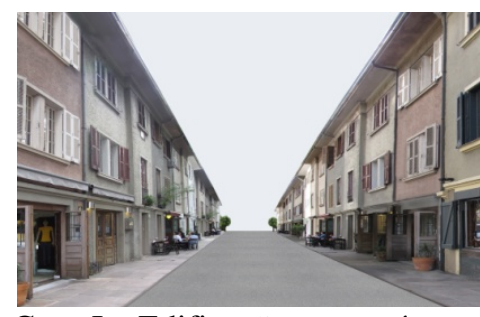

Cena I - Edificações no perímetro da quadra com janelas e portas voltadas para a rua 
Tabela 7 - Graus de satisfação com as cenas urbanas G, H e I

\begin{tabular}{l|c|c|c|c|c|c|c}
\hline & $\begin{array}{c}\text { Muito } \\
\text { bonita }\end{array}$ & Bonita & $\begin{array}{c}\text { Nem bonita, } \\
\text { nem feia }\end{array}$ & Feia & Muito feia & $\begin{array}{c}\text { mvo } \\
\text { Kendall }\end{array}$ & $\begin{array}{c}\text { mvo } \\
\text { K-W }\end{array}$ \\
\hline \multicolumn{7}{c}{ Arquitetos (total de respondentes para cada cena: G=48; H=48; I =49) } \\
\hline Cena G & $6(12.5)$ & $19(39.6)$ & $16(33.3)$ & $6(12.5)$ & $1(2.1)$ & 1.97 & 61.93 \\
\hline Cena H & $1(2.1)$ & $18(37.5)$ & $20(41.7)$ & $9(18.8)$ & 0.0 & 1.74 & 83.48 \\
\hline Cena I & $9(18.4)$ & $27(55.1)$ & $11(22.4)$ & $1(2)$ & $1(2)$ & 2.29 & 103.18 \\
\hline Não arquitetos com formação (total de respondentes para cada cena: G=124; H=124; I=130) \\
\hline Cena G & $42(33.9)$ & $66(53.2)$ & $14(11.3)$ & $2(1.6)$ & 0.0 & 2.49 & 100.56 \\
\hline Cena H & $3(2.4)$ & $58(46.8)$ & $45(36.3)$ & $16(12.9)$ & $2(1.6)$ & 1.64 & 92.48 \\
\hline Cena I & $19(14.6)$ & $64(49.2)$ & $27(20.8)$ & $17(13.1)$ & $3(2.3)$ & 1.88 & 90.94 \\
\hline \multicolumn{7}{|c|}{ Pessoas sem formação (total de respondentes para cada cena: G=10; H=10; I= 10) } \\
\hline Cena G & $6(60)$ & $3(30)$ & $1(10)$ & 0.0 & 0.0 & 2.50 & 121.15 \\
\hline Cena H & $2(20)$ & $5(50)$ & $2(20)$ & $1(10)$ & 0.0 & 1.75 & 117.85 \\
\hline Cena I & $1(10)$ & $8(80)$ & 0.0 & $1(10)$ & 0.0 & 1.75 & 107.70 \\
\hline
\end{tabular}

Nota: $\mathrm{mvo}$ Kendall $=$ media dos valores ordinais obtidos por meio do teste Kendall $\mathrm{W}$ (valores devem ser comparados para cada um dos três grupos de respondentes; valor mais alto indica cena mais satisfatória); mvo K-W = média dos valores ordinais obtidos por meio do teste Kruskal-Wallis (valores devem ser comparados para cada um dos três tipos de cenas; valor mais alto indica cena mais satisfatória); os valores entre parênteses representam porcentagens em relação ao número total de respondentes em cada cena; o número de respondentes pode variar em relação à avaliação de cada cena, já que algumas perguntas não foram respondidas por todos em cada um dos três grupos.

Como resultado da avaliação individual de cada cena, foi encontrada uma diferença estatisticamente significativa entre as avaliações das cenas urbanas G, H e I por arquitetos (Kendall $\mathrm{W}$, teste estatístico $=12.330$, sig. $=0,002)$, e por não arquitetos com formação universitária (Kendall W, teste estatístico $=70,542$, sig. $=$ 0,000), não havendo diferença estatisticamente significativa entre as avaliações realizadas por aqueles sem tal formação (teste Kendall W). A cena I (edificações no perímetro da quadra com portas e janelas voltadas para a rua; $73,5 \%$ de avaliações positivas e $4 \%$ de negativas) é a mais bem avaliada e a cena $\mathrm{H}$ (condomínio fechado com muro verde junto à rua e edificações no perímetro da quadra com portas e janelas voltadas para a rua; $39,6 \%$ de avaliações positivas e 18,8\% de negativas) é a mais mal avaliada pelos arquitetos (Figura 7 E Tabela 7). Enquanto a cena H (49,2\% de avaliações positivas e $14,5 \%$ de negativas) também é a mais mal avaliada pelos não arquitetos com formação universitária, a cena G (condomínios fechados com muros verdes junto à rua; $87,1 \%$ de avaliações positivas e 1,6\% de negativas) é a mais bem avaliada por esse grupo (Tabela 7).

Uma diferença estatisticamente significativa também foi encontrada entre a ordem de preferência das cenas urbanas $\mathrm{G}, \mathrm{H}$ e I pelos arquitetos (Kendall W, teste estatístico = 9.489, sig. $=0,009)$, pelos não arquitetos com formação universitária (Kendall W, teste estatístico = 73.882 , sig. $=0,000)$ e por aqueles sem tal formação (Kendall W, teste estatístico $=7.200$, sig. $=0,027)$. Confirmando os resultados anteriores sobre avaliações de cenas individuais, a cena I (edificações no perímetro da quadra com portas e janelas voltadas para a rua) é a preferida e a cena $\mathrm{H}$ (condomínio fechado com muro verde junto à rua e edificações no perímetro da quadra com portas e janelas voltadas para a rua) é a menos preferida pelos arquitetos, e a cena G (condomínios fechados com muros verdes junto à rua) é a preferida pelos não arquitetos com formação universitária. No entanto, a cena I, e não a cena $\mathrm{H}$ (que recebeu a pior avaliação individual), é a menos preferida por este grupo. Aqueles sem formação universitária também têm maior preferência pela cena $G$ e menor preferência pela cena I (Tabela 8). A cena I é a preferida pela clara maioria dos arquitetos (27), basicamente devido à indicação, por 88,9\% destes, da presença de edificações com aberturas voltadas para a rua (Tabela 9). Por sua vez, a cena G é a preferida pelos outros dois grupos, principalmente devido à existência de áreas gramadas (selecionada por 81,3\% de 91 não arquitetos com formação universitária e por $85,7 \%$ de 7 daqueles sem tal formação) e de árvores (indicada por 70,3\% de 91 não arquitetos com formação universitária e por 42,9\% de 10 daqueles sem formação). A cena H é a menos preferida por parte dos arquitetos, principalmente devido à presença de muros, justificativa esta selecionada por $60 \%$ de 15 arquitetos (Tabela 9). Por outro lado, o fato de a cena I ser a menos preferida pelos outros dois grupos deve-se à inexistência de áreas gramadas (indicada por $72 \%$ de 75 não arquitetos com formação superior e por $71,4 \%$ de 7 daqueles sem tal formação) e de árvores (selecionada por 72\% de

268 Reis, A. T. da L.; Panzenhagen, A. F. P.; Gerson, V. L. C. 
75 não arquitetos com formação superior e por $71,4 \%$ de 7 daqueles sem tal formação). Mesmo assim, a cena I é avaliada positivamente por $90 \%$ daqueles sem formação universitária e por $63,8 \%$ dos não arquitetos com formação.

Uma diferença estatisticamente significativa também foi encontrada entre as avaliações das cenas urbanas $\mathrm{J}$ (Kruskal-Wallis, teste estatístico = 16.315 , sig. $=0,000)$ e K (teste de Kruskal-Wallis, teste estatístico $=12,50$, sig. $=0,002$ ) pelos arquitetos, não arquitetos graduados, e não graduados, não tendo sido encontrada diferença estatisticamente significativa entre as avaliações da cena L (edificações no perímetro da quadra com janelas e portas voltadas para a rua) por estes grupos (teste Kruskal-Wallis), cena esta que é avaliada positivamente por pelo menos $63 \%$ dos respondentes em cada um destes três grupos
(Figura 8; Tabela 10). A cena urbana J (portas de garagens voltadas para a rua) é mais bem avaliada por aqueles sem formação (20\% de avaliações positivas e $30 \%$ de negativas) e mais mal avaliada pelos arquitetos ( $0 \%$ de avaliações positivas e 89,4\% de avaliações negativas). A cena urbana $\mathrm{K}$ (portas de garagens voltadas para a rua e edificações no perímetro da quadra com portas e janelas voltadas para a rua) também é mais bem avaliada por aqueles sem formação (40\% de avaliações positivas e $10 \%$ de negativas), mas é mais mal avaliada pelos não arquitetos com formação universitária (8,3\% de avaliações positivas e 50,8\% de negativas) (Tabela 10). Contudo, essas duas cenas ( $\mathrm{J}$ e $\mathrm{K}$ ) podem ser consideradas como esteticamente negativas, embora a intensidade das avaliações negativas entre os três grupos de respondentes varie.

\section{Tabela 8 - Ordem de preferência quanto à aparência}

\begin{tabular}{c|c|c|c|c|c|c|c|c}
\hline \multicolumn{2}{c|}{ Arquitetos (48 respondentes) } & \multicolumn{2}{c|}{$\begin{array}{c}\text { Não arquitetos com formação } \\
\text { (121 respondentes) }\end{array}$} & \multicolumn{2}{c}{$\begin{array}{c}\text { Pessoas sem formação (10 } \\
\text { respondentes) }\end{array}$} \\
\hline Cena & mvo K & mvo K-W & Cena & mvo K & mvo K-W & Cena & mvo K & mvo K-W \\
\hline $\mathrm{G}(101)$ & 2.13 & 117.55 & $\mathrm{G}(168)$ & 1.38 & 79.73 & $\mathrm{G}(14)$ & 1.40 & 82.05 \\
\hline $\mathrm{H}(105)$ & 2.23 & 93.28 & $\mathrm{H}(258)$ & 2.17 & 87.66 & $\mathrm{H}(20)$ & 2.00 & 76.10 \\
\hline $\mathrm{I}(77)$ & 1.64 & 56.38 & $\mathrm{I}(292)$ & 2.45 & 99.61 & $\mathrm{I}(26)$ & 2.60 & 107.25 \\
\hline
\end{tabular}

Nota: mvo $\mathrm{K}=$ média dos valores ordinais obtidos por meio do teste de Kendall W; estes valores devem ser comparados na coluna, considerando-se o menor valor como indicador da maior preferência; mvo $\mathrm{K}-\mathrm{W}=$ média dos valores ordinais obtidos por meio do teste Kruskal-Wallis; estes valores devem ser comparados na linha de cada cena, considerando-se 0 menor valor como indicador da maior preferência; os valores entre parênteses representam o somatório dos pontos recebidos por cada cena em cada um dos três grupos de respondentes, com cada um destes atribuindo valores de 1 (para a cena preferida) a 3 (para a cena menos preferida); assim, quanto menor o valor entre parênteses, maior a preferência pela cena.

\section{Tabela 9 - J ustificativas quanto às preferências pelas cenas}

\begin{tabular}{l|c|c|c}
\hline \multicolumn{1}{c|}{ Justificativa } & $\begin{array}{c}\text { Arquitetos } \\
\text { (A) }\end{array}$ & $\begin{array}{c}\text { Não arquitetos com } \\
\text { formação (NAG) }\end{array}$ & $\begin{array}{c}\text { Pessoas sem } \\
\text { formação (SG) }\end{array}$ \\
\hline \multicolumn{1}{c|}{ Cena mais preferida = I (arquitetos = 27; não arquitetos com formação = 21; pessoas sem formação = 1) } \\
\hline Presença de edificações com aberturas para a rua & $88,9(24)$ & $66,7(14)$ & $100(1)$ \\
\hline \multicolumn{2}{|c|}{ Cena mais preferida = G (arquitetos = 17; não arquitetos com formação = 91; pessoas sem formação = 7) } \\
\hline Presença de edificações com abertura para a rua & $29,4(5)$ & $19,8(18)$ & 0 \\
\hline Existência de áreas gramadas & $64,7(11)$ & $81,3(74)$ & $85,7(6)$ \\
\hline Existência de árvores & $64,7(11)$ & $70,3(64)$ & $42,9(3)$ \\
\hline Cena menos preferida = H (arquitetos = 15; não arquitetos com formação = 28; pessoas sem formação = 2) \\
\hline Presença de muros & $60(9)$ & $17,9(5)$ & 0 \\
\hline Inexistência de área gramada & $20(3)$ & $10,7(3)$ & $50(1)$ \\
\hline Inexistência de árvores & $26,7(4)$ & $14,3(4)$ & 0 \\
\hline Mistura de estilos entre os dois lados da rua & $33,3(5)$ & $57,1(16)$ & $50(1)$ \\
\hline Cena menos preferida = I (arquitetos = 10; não arquitetos com formação = 75; pessoas sem formação = 7) \\
\hline Inexistência de área gramada & $70(7)$ & $72(54)$ & $71,4(5)$ \\
\hline Inexistência de árvores & $50(5)$ & $72(54)$ & $14,3(1)$ \\
\hline
\end{tabular}

Nota: os valores fora dos parênteses representam percentuais em relação ao total de respondentes em cada um dos três grupos que indicou a cena como mais ou menos preferida; são apresentadas as justificativas mencionadas pelo menos por $20 \%$ dos respondentes em um dos três grupos. 
Figura 8 - Cenas urbanas J, K e L

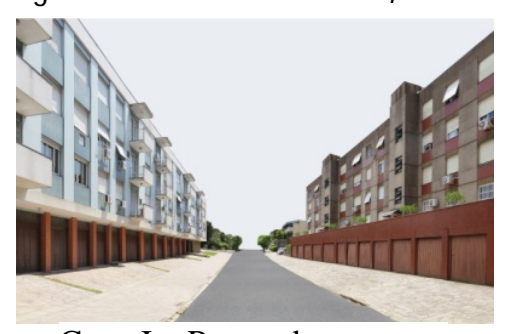

Cena J - Portas de garagens voltadas para a rua

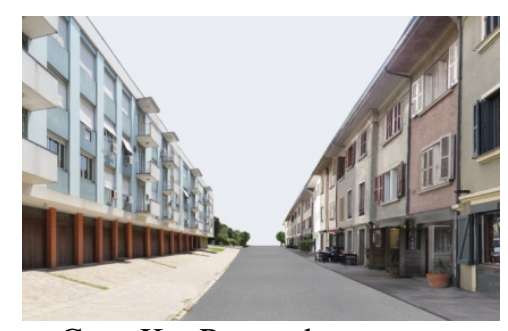

Cena $\mathrm{K}$ - Portas de garagens voltadas para a rua - edificações no perímetro da quadra com janelas e portas voltadas para a

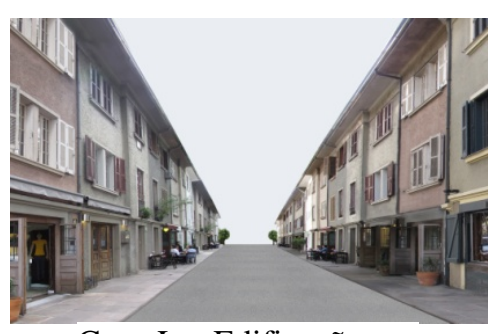

Cena L - Edificações no perímetro da quadra com janelas e portas voltadas para a rua

rua

Tabela 10 - Graus de satisfação com cenas urbanas J , K e L

\begin{tabular}{l|c|c|c|c|c|c|c}
\hline & $\begin{array}{c}\text { Muito } \\
\text { Bonita }\end{array}$ & Bonita & $\begin{array}{c}\text { Nem bonita, } \\
\text { nem feia }\end{array}$ & Feia & Muito Feia & mvo Kendall & $\begin{array}{c}\text { mvo } \\
\text { K-W }\end{array}$ \\
\hline \multicolumn{7}{c}{ Arquitetos (número total de respondentes em cada cena: J=47; K=47; L=49) } \\
\hline Cena J & 0.0 & 0.0 & $5(10.6)$ & $28(59.6)$ & $14(29.8)$ & 1.15 & 73.32 \\
\hline Cena K & 0.0 & $5(10.6)$ & $27(57.4)$ & $13(27.7)$ & $2(4.3)$ & 1.98 & 98.22 \\
\hline Cena L & $9(18.4)$ & $27(55.1)$ & $11(22.4)$ & $1(2)$ & $1(2)$ & 2.87 & 103.18 \\
\hline Não arquitetos com formação (número total de respondentes em cada cena: J=120; K=120; L=130) \\
\hline Cena J & $1(0.8)$ & $2(1.7)$ & $29(24.2)$ & $64(53.3)$ & $24(20)$ & 1.44 & 91.12 \\
\hline Cena K & 0.0 & $10(8.3)$ & $49(40.8)$ & $52(43.3)$ & $9(7.5)$ & 1.83 & 81.92 \\
\hline Cena L & $19(14.6)$ & $64(49.2)$ & $27(20.8)$ & $17(13.1)$ & $3(2.3)$ & 2.72 & 90.94 \\
\hline Pessoas sem formação universitária (número total de respondentes em cada cena: J=10; K=10; L=10) \\
\hline Cena J & 0.0 & $2(20)$ & $5(50)$ & $3(30)$ & 0.0 & 1.50 & 137.20 \\
\hline Cena K & 0.0 & $4(40)$ & $5(50)$ & $1(10)$ & 0.0 & 2.00 & 130.65 \\
\hline Cena L & $1(10)$ & $8(80)$ & 0.0 & $1(10)$ & 0.0 & 2.50 & 107.70 \\
\hline
\end{tabular}

Nota: Mvo Kendall = media dos valores ordinais obtidos por meio do teste Kendall W (valores devem ser comparados para cada um dos três grupos de respondentes; valor mais alto indica cena mais satisfatória); mvo $\mathrm{K}$ - $\mathrm{W}=$ média dos valores ordinais obtidos por meio do teste Kruskal-Wallis (valores devem ser comparados para cada um dos três tipos de cenas; valor mais alto indica cena mais satisfatória); os valores entre parênteses representam porcentagens em relação ao número total de respondentes em cada cena; o número de respondentes pode variar em relação à avaliação de cada cena, já que algumas perguntas não foram respondidas por todos em cada um dos três grupos.

Uma diferença estatisticamente significativa foi encontrada entre as avaliações das cenas urbanas J, $\mathrm{K}$ e L pelos arquitetos (Kendall W, teste estatístico $=80.049$, sig. $=0,000)$, pelos não arquitetos com formação universitária (Kendall W, teste estatístico $=140.768$, sig. $=0,000)$ e por aqueles sem tal formação (Kendall W, teste estatístico $=7.692$, sig. $=0,021)$. Em qualquer um destes três grupos, a cena $\mathrm{L}$ é a melhor e a cena $\mathrm{J}$ é a mais mal avaliada (Tabela 10).

Uma diferença estatisticamente significativa também foi encontrada entre a ordem de preferência das cenas urbanas $\mathrm{J}, \mathrm{K}$ e $\mathrm{L}$ pelos arquitetos (Kendall W, teste estatístico $=64.478$, sig. $=0,000)$ e pelos não arquitetos graduados (Kendall W, teste estatístico $=99.770$, sig. $=$ 0,000). Confirmando os resultados anteriores, a cena L (edificações no perímetro da quadra com janelas e portas voltadas para a rua) é a mais preferida e a cena $\mathrm{J}$ (portas de garagens voltadas para a rua) é a menos preferida por esses dois grupos (Tabela 11). As principais razões para preferir a cena L são a presença de edificações com aberturas para a rua (indicada por $64,3 \%$ de 42 arquitetos, 52,2\% de 90 não arquitetos com formação, e por $57,1 \%$ de 7 pessoas sem formação) e a relação direta da edificação com a rua, selecionada por $73,8 \%$ de 42 arquitetos, $58,9 \%$ de 90 não arquitetos com formação, e por $57,1 \%$ de 7 pessoas sem formação. Por outro lado, os principais motivos para a cena $\mathrm{J}$ ser a menos preferida são a presença de muros (indicada por $61,9 \%$ de 42 arquitetos, 50,6\% de 87 não arquitetos com formação, e por $71,4 \%$ de 7 pessoas sem formação) e a falta de relação direta entre as edificações e a rua, indicada por $61,9 \%$ de 42 arquitetos, 51,7\% de 21 não arquitetos com formação, e por $57,1 \%$ de 10 pessoas sem formação (Tabela 12). 
Tabela 11 - Ordem de preferência quanto à aparência

\begin{tabular}{c|c|c|c|c|c|c|c|c}
\hline \multicolumn{2}{c|}{ Arquitetos (47 respondentes) } & \multicolumn{2}{c|}{$\begin{array}{c}\text { Não arquitetos com formação } \\
\text { (114 respondentes) }\end{array}$} & \multicolumn{2}{c}{$\begin{array}{c}\text { Pessoas sem formação (10 } \\
\text { respondentes) }\end{array}$} \\
\hline Cena & mvo K & mvo K-W & Cena & mvo K & mvo K-W & Cena & mvo K & mvo K-W \\
\hline $\mathrm{J}(133)$ & 2.83 & 94.24 & $\mathrm{~J}(302)$ & 2.65 & 83.39 & $\mathrm{~J}(25)$ & 2.50 & 77.05 \\
\hline $\mathrm{K}(93)$ & 2.02 & 84.27 & $\mathrm{~K}(233)$ & 2.04 & 86.23 & $\mathrm{~K}(20)$ & 2.00 & 82.80 \\
\hline $\mathrm{L}(53)$ & 1.15 & 77.70 & $\mathrm{~L}(153)$ & 1.32 & 88.44 & $\mathrm{~L}(15)$ & 1.50 & 96.15 \\
\hline
\end{tabular}

Nota: mvo $\mathrm{K}=$ média dos valores ordinais obtidos por meio do teste de Kendall W; estes valores devem ser comparados na coluna, considerando-se o menor valor como indicador da maior preferência; mvo K-W = média dos valores ordinais obtidos por meio do teste Kruskal-Wallis; estes valores devem ser comparados na linha de cada cena, considerando-se o menor valor como indicador da maior preferência; os valores entre parênteses representam o somatório dos pontos recebidos por cada cena em cada um dos três grupos de respondentes, com cada um destes atribuindo valores de 1 (para a cena preferida) a 3 (para a cena menos preferida); assim, quanto menor o valor entre parênteses, maior a preferência pela cena.

Tabela 12 - J ustificativa quanto à preferência da cena

\begin{abstract}
\begin{tabular}{l|}
\hline \multicolumn{2}{c|}{ Justificativa } \\
\hline Cena mais preferida - L (arquitetos = 42; não arq \\
\hline Presença de edificação com abertura para a rua \\
\hline \multicolumn{2}{c}{ Relação direta da edificação com a rua } \\
\hline Cena menos preferida - J (arquitetos = 42; não arq de muros \\
\hline \multicolumn{3}{c}{ Falta de relação direta entre edificação e rua } \\
Nota: os valores fora dos parênteses representam percen \\
grupos que indicou a cena como mais ou menos preferida; \\
por 20\%dos respondentes em um dos três grupos. \\
Embora não tenha sido encontrada diferença \\
estatisticamente significativa (Kendall W), as
\end{tabular} preferências dos não graduados seguem as dos outros dois grupos. Assim, tanto para as pessoas com educação universitária como para aquelas sem tal formação, as portas de garagens voltadas para a rua provocam, claramente, reações estéticas negativas, enquanto as edificações nos perímetros dos blocos com portas e janelas voltadas para a rua tendem a gerar reações estéticas positivas.
\end{abstract}

\section{Conclusões}

Diferenças estatisticamente significativas entre as avaliações estéticas pelos três grupos de respondentes foram encontradas em oito das 12 cenas que representam distintas interfaces urbanas, que são mais bem avaliadas por pessoas sem formação universitária e tendem a ser mais mal avaliadas pelos arquitetos, nomeadamente: edificações no interior do quarteirão sem relação direta com a rua; edificações no perímetro do quarteirão com portas e janelas voltadas para a rua; edifícios com empena cega voltada para a rua; condomínios fechados com muros junto à rua; condomínio fechado com muro junto à rua e edificações no perímetro do quarteirão com portas e janelas voltadas para a rua; condomínios fechados com muros verdes junto à rua; portas de garagens voltadas para a rua; portas de garagens voltadas para a rua e edificações no perímetro do bloco com portas e as janelas voltadas para a rua. O fato de as avaliações estéticas mais positivas serem de pessoas sem formação universitária e das menos positivas tender a ser de arquitetos é corroborado pelos resultados de outros estudos que tratam de avaliações estéticas de cenas urbanas e de fachadas individuais de edificações por parte de arquitetos, não arquitetos com formação universitária e pessoas sem formação universitária (REIS; BIAVATTI; PEREIRA, 2011 e 2014). Tal fato pode ser explicado pelo provável maior grau de exigência dos arquitetos em suas avaliações estéticas devido a uma formação acadêmica relacionada à estética, enquanto aqueles sem formação universitária parecem ser menos exigentes em suas avaliações estéticas. No entanto, as avaliações positivas de algumas cenas não são expressivas mesmo para aqueles sem formação universitária, indicando que as diferenças encontradas entre os três grupos tendem a estar na intensidade das avaliações negativas (ou positivas) e não em avaliações estéticas opostas.

As cenas que geraram as melhores respostas estéticas são constituídas pelas seguintes interfaces: edifícios no interior da quadra sem relação direta com a rua (por parte dos não 
arquitetos), principalmente devido à percepção dos respondentes da presença de aberturas e relacionamento direto com a rua; edifícios no perímetro da quadra com portas e janelas voltadas para a rua (principalmente por parte dos arquitetos) devido à presença de aberturas voltadas para a rua e à relação direta entre os prédios e a rua; condomínios fechados com muros verdes junto à rua (por parte dos não arquitetos) devido à existência de áreas gramadas e árvores. Mesmo não gerando respostas estéticas por parte dos não arquitetos mais positivas do que aquelas acerca das cenas com interfaces constituídas por condomínios fechados com muros verdes junto à rua e com a combinação de condomínio fechado com muro verde junto à rua e edificações no perímetro da quadra com janelas e portas voltadas para a rua, a cena caracterizada por edificações no perímetro da quadra com janelas voltadas para a rua é avaliada positivamente pela expressiva maioria das pessoas sem formação universitária e pela maioria dos não arquitetos com formação universitária.

Por sua vez, as cenas que provocaram as piores respostas estéticas são constituídas pelas seguintes interfaces: edifícios com empena cega voltada para a rua (por parte dos três grupos), devido à presença de muros ou empenas cegas e falta de relação direta com a rua; condomínios fechados com muros junto à rua (por aqueles com formação universitária), fundamentalmente, devido à presença de muros ou paredes cegas; condomínio fechado com muro verde junto à rua e edificações no perímetro da quadra com janelas e portas voltadas para a rua (por aqueles com educação universitária) devido à presença de muros ou paredes cegas; portas de garagens voltadas para a rua (pelos três grupos), devido à presença de muros ou paredes cegas e à falta de relação direta entre as edificações e a rua. Ainda, os resultados apresentados evidenciam que as avaliações e preferências estéticas, assim como as justificativas para tais preferências não foram afetadas pelas variações nas perspectivas das cenas (incluindo diferenças nas larguras das ruas), corroborando o argumento de que os ângulos de visão utilizados para as fotografias não têm um efeito significativo sobre as avaliações estéticas (STAMPS, 2000).

Concluindo, as interfaces urbanas caracterizadas pela presença de muros ou paredes cegas, devido à falta de estímulo visual destes elementos, conforme já evidenciado em outros estudos (BECKER; REIS, 2004; REIS; SEADI; BIAVATTI, 2016), e a falta de relação direta entre as edificações e a rua tendem a ser avaliadas negativamente por qualquer um dos três grupos, embora as avaliações estéticas negativas daqueles sem formação universitária tendam a ser menos intensas. Logo, interfaces destituídas ou com baixo nível de estímulos estéticos, tais como muros, empenas cegas e portas de garagens, tendem a não contribuir para a atração de pedestres e a não favorecer o movimento e a permanência de pessoas nos espaços abertos públicos e, portanto, deveriam ser evitadas, principalmente em áreas urbanas consolidadas. Neste sentido, condomínios horizontais e verticais murados deveriam ser evitados em tais áreas urbanas. Ainda, conforme já destacado em outros estudos (GEHL, 2010; JACOBS, 1984), a própria presença de pessoas nos espaços abertos públicos torna tais espaços mais atraentes para outras pessoas.

Por outro lado, as interfaces urbanas caracterizadas pela presença de edificações com aberturas voltadas para a rua e pela relação direta entre o prédio e a rua tendem a ser positivamente avaliadas pelos três grupos, corroborando o que consta na literatura acerca da importância deste tipo de interface para a qualidade dos espaços urbanos (BENTLEY et al., 2005; GEHL, 2010; JACOBS, 1984). Logo, estes resultados tendem a não sustentar aqueles de estudos que revelam a existência de diferenças entre as avaliações estéticas de arquitetos e de leigos (FAWCETT; ELLINGHAM; PLATT, 2008; NASAR, 1998), e a corroborar aqueles que não revelam diferenças significativas entre avaliações estéticas de arquitetos, não arquitetos com formação universitária e pessoas sem tal formação (REIS; BIAVATTI; PEREIRA, 2011, 2014). Contudo, cenas com a existência de áreas gramadas e árvores podem ser preferidas pelos não arquitetos em comparação a cenas caracterizadas por edificações com aberturas voltadas para a rua, o que reforça a importância da vegetação para qualificar o espaço urbano, conforme tem sido evidenciada em diversos estudos (KAPLAN, 2001; REIS; BARCELOS, 2011; SCHVARSTZHAUPT; REIS, 2017). Assim, sem desconsiderar as limitações deste trabalho com relação à quantidade de diferentes tipos de interfaces e de cenas representando cada tipo de interface, esses resultados contribuem para a compreensão dos efeitos estéticos produzidos por distintas interfaces urbanas e, portanto, para um desenho urbano que qualifique as experiências estéticas dos usuários dos espaços abertos públicos. Contudo, salienta-se a importância da realização de novos estudos que tratem de avaliações estéticas de distintas interfaces urbanas baseadas em novas representações, visando o aprofundamento do conhecimento acerca das percepções estéticas de interfaces em distintos contextos urbanos. 


\section{Referências}

ARSEGO, C.; REIS, A.T. Interfaces Térreas e Atividades nos Espaços Abertos. In: SIMPÓSIO BRASILEIRO DE QUALIDADE DO PROJETO NO AMBIENTE CONSTRUÍDO, 5., João Pessoa, 2017. Anais... Porto Alegre: ANTAC. 2017.

BECKER, D.; REIS, A. O Impacto das Barreiras Físicas de Condomínios Horizontais Fechados no Espaço Urbano. In: CONFERÊNCIA LATINO AMERICANA DE CONSTRUÇÃO SUSTENTÁVEL; ENCONTRO NACIONAL DE TECNOLOGIA DO AMBIENTE CONSTRUÍDO, 10., São Paulo, 2004. Anais... São Paulo: ANTAC, 2004.

BENTLEY, I. et al. Responsive Environments: a manual for designers. Oxford: Elsevier, 2005.

FAWCETT, W.; ELLINGHAM, I.; PLATT, S. Reconciling the Architectural Preferences of Architects and the Public: the ordered preference model. Environment and Behavior, v. 40, n. 5, p. 599-618, set. 2008.

GEHL, J. Life Between Buildings: using public space. Washington: Island Press, 2011.

GEHL, J. Cities for People. Washington: Island Press, 2010.

\section{JACOBS, J. The Death and Life of Great}

American Cities: the failure of town planning. Harmondsworth: Penguin Books, 1984.

KAPLAN, R. The Nature of the View from Home: psychological benefits. Environment and Behavior, v. 33, n. 4, p. 507-542, 2001.

NASAR, J. The Evaluative Image of the City. Thousand Oaks: Sage, 1998.

REIS, A. Forma Urbana Tradicional e Modernista: uma reflexão sobre o uso e estética dos espaços urbanos. ARQUISUR Revista, v. 6, p. 70-87, 2014a.

REIS, A. Urban Form and Its Implication for the Use of Urban Spaces. In: OLIVEIRA, V. et al. (Eds.). Our Common Future in Urban Morphology. Porto: FEUP, 2014b.
REIS, A. T.; BARCELOS, A. Green Spaces, Vegetation, and Well-Being in the Housing Environment. In: BONAIUTO, M. et al. (Eds.). Urban Diversities Environmental and Social Issues - Series: advances in people-environment studies, volume 2. Göttingen: Hogrefe Publishing, 2011.

REIS, A.; BIAVATTI, C.; PEREIRA, M. L. Composição Arquitetônica e Qualidade Estética. Ambiente Construído, Porto Alegre, v. 14, n. 1, p. 191-213, jan./mar. 2014.

REIS, A.; BIAVATTI, C., PEREIRA, M. L. Estética Urbana: uma análise através das ideias de ordem, estímulo visual, valor histórico e familiaridade. Ambiente Construído, Porto Alegre, v. 11, n. 4, p. 185-204, out./dez. 2011.

REIS, A.; LAY, M. C. Avaliação da Qualidade de Projetos: uma abordagem perceptiva e cognitiva.

Ambiente Construído, Porto Alegre, v. 6, n. 3, p. 21-34, jul./set. 2006.

REIS, A. T.; SEADI, M. L.; BIAVATTI, C. Views from Apartment Buildings: an analysis by architects and non-architects college graduates. In: ANNUAL CONFERENCE OF THE ENVIRONMENTAL DESIGN RESEARCH ASSOCIATION, 47., Raleigh, 2016. Proceedings... Raleigh: EDRA, 2016.

SANOFF, H. Visual Research Methods in Design. New York: Van Nostrand Reinhold, 1991.

SCHVARSTZHAUPT, C. C.; REIS, A. T. Vegetação Urbana e Instrumentos Legais. In: ENCONTRO NACIONAL DA ASSOCIAÇÃO NACIONAL DE PÓS-GRADUAÇÃO E PESQUISA EM PLANEJAMENTO URBANO E REGIONAL: DESENVOLVIMENTO, CRISE E RESISTÊNCIA: QUAIS OS CAMINHOS DO PLANEJAMENTO URBANO E REGIONAL? 17., São Paulo, 2017. Anais... São Paulo: ENANPUR, 2017.

STAMPS, A. Psychology and the Aesthetics of the Built Environment. Massachusetts: KAP, 2000.

TRANCIK, R. Finding Lost Space: theories of urban design. New York: Van Nostrand Reinhold, 1986. 


\section{Antônio Tarcísio da Luz Reis}

Departamento de Arquitetura, Faculdade de Arquitetura | Universidade Federal do Rio Grande do Sul| Rua Sarmento Leite, 320, Centro Porto Alegre - RS - Brasil | CEP 90050-170 | Tel.: (51) 3316-4529 | E-mail: tarcisio@orion.ufrgs.br

\section{Ana Flávia Piva Panzenhagen}

Faculdade de Arquitetura | Universidade Federal do Rio Grande do Sul | Tel.: (51) - 99867-5399 | E-mail: ppanzenhagen@gmail.com

\section{Victoria Luvizetto Carpin Gerson}

Faculdade de Arquitetura | Universidade Federal do Rio Grande do Sul | Tel.: (51) - 99433-6556 | E-mail: victoriaufrgs@gmail.com

\section{Revista Ambiente Construído}

Associação Nacional de Tecnologia do Ambiente Construído

Av. Osvaldo Aranha, 99 - 3o andar, Centro

Porto Alegre - RS - Brasil

CEP 90035-190

Telefone: +55 (51) 3308-4084

Fax: +55 (51) 3308-4054

www. seer. ufrgs. br/ ambienteconstruido

E-mail: ambienteconstruido@ufrgs.br

This is an open-access article distributed under the terms of the Creative Commons Attribution License.

274 Reis, A. T. da L.; Panzenhagen, A. F. P.; Gerson, V. L. C. 